\title{
EL ARTE Y SU PODER TRANSFORMADOR. INCONSCIENTE, EMOCIONES Y CREACIÓN SEGÚN LA PERSPECTIVA JUNGUIANA
}

\section{Art and its transformative power. Unconscious, emotions and creation according to junguian perspective}

\section{Rocío Hernández-Mella}

Profesora-investigadora del Área de Ciencias Sociales y Humanidades del Instituto Tecnológico de Santo Domingo (INTEC), República Dominicana

Correo-e: rocio.hernandez@intec.edu.do https://orcid.org/0000-0002-1331-5453

\section{Patricia D'Meza-Pérez}

Egresada de la carrera de Psicología del INTEC, República Dominicana

Correo-e: patricia.dmeza@gmail.com

\section{Nicole Ramírez-Jiménez}

Egresada de la carrera de Psicología del INTEC, República Dominicana

Correo-e: nicoleramirez0528.nr@gmail.com

\section{Jose Morel-Camacho}

Egresado de la carrera de Psicología del INTEC, Repú-

blica Dominicana

Correo-e: nojose28@hotmail.com

\section{Laura Peña-Lantigua}

Egresada de la carrera de Psicología del INTEC, Repú-

blica Dominicana

Correo-e: laurapena1497@gmail.com

\section{Cynthia Olivier-Sterling}

Egresada de la carrera de Psicología del INTEC, Repú-

blica Dominicana

Correo-e: cynthia.olivier.sterling@gmail.com

Recibido: 13/09/2019 • Aprobado: 8/10/2019

Cómo citar: Hernández-Mella, R., D’Meza-Pérez, P., Ramírez-Jiménez, N., Morel-Camacho, J., Peña-Lantigua, L., \& Olivier-Sterling, C. (2020). El arte y su poder transformador. Inconsciente, emociones y creación según la perspectiva junguiana. Ciencia y Sociedad, 45(1), 25-34. Doi: https://doi.org/10.22206/cys.2020.v45i1.pp25-34

Resumen

Este ensayo analiza cómo la creatividad otorga a la conciencia una fuerza renovadora y cómo su poder transformador proviene del nivel inconsciente de la psique, como se explica en la Psicología Analítica de Carl Jung y sus seguidores. En particular, se centra en mostrar cómo en el estrato más profundo del inconsciente se genera una creación visionaria que convierte al creador en una especie de medium consumido por un impulso superior a su fuerza. Un impulso, que puede expresarse en una obra artística o exteriorizarse en un brote de locura cuando no se comprende el significado profundo de la experiencia creativa en el self. El artículo también analiza la creación en sus relaciones con el desarrollo humano en el contexto de la Psicología Analítica y su conceptualización como individuación. En ese sentido, destaca cómo, a través de

\section{Abstract}

This essay analyzes how creativity gives consciousness a renewing force and how its transforming power comes from the unconscious level of the psyche, as explained by the Analytical Psychology of Carl Jung and his followers. In particular, it focuses on showing how in the deepest stratum of the unconscious, a visionary creation is generated to turns the creator into a kind of medium consumed by an impulse superior to his strength. An impulse that can be expressed in an artistic work or externalized in an outbreak of madness when the deep meaning of the creative experience in the self is not understood. The article also analyzes the creation in its relations with human development in the context of Analytical Psychology and his conceptualization as individuation. In that sense, highlight how, through the emotions that a work of art manages to 


\section{Rocío Hernández-Mella, Patricia D’Meza-Pérez, Nicole Ramírez-Jiménez, Jose Morel-Camacho, Laura Peña-Lantigua y Cynthia Olivier-Sterling}

las emociones que una obra de arte consigue despertar en el espectador, el artista logra establecer una comunicación con su público.

Palabras clave: creatividad; inconsciente; emociones; arte.

\section{Introducción}

El arte es sobre todo un estado del alma. Marc Chagal

La génesis de la creación artística constituye el interés central de este trabajo. Se trata de un acto de transformación al cual se otorga un poder que tanto construye como destruye, pero siempre desarrolla el ser esencial, es decir, aquel que incluye en su existencia la expresión más honda de sí mismo. En sus diferentes apartados, el texto se centra en el proceso creador y el papel que el inconsciente juega en ello, así como en las emociones y su fuerza expresiva. Ambos elementos psicológicos, entrelazados por la producción creativa o la obra artística, tienen un rol esencial junto al juego y la imaginación.

Debido a esa fuerza generada en la psique que origina la acción creativa, da sentido a la redención de la figura del daimon, la que los griegos planteaban como mediador entre dioses y mortales, con sus cualidades positivas y negativas, propuesta por los analistas junguianos. Esto así, porque aún en los casos en que la presión de la psique llegue a paralizar al individuo, ella será parte de su camino por la vida y redundará en la motivación interna para su realización.

En cuanto a las emociones, estas están intrincadas en el juego y en la imaginación desde la infancia, según lo exponen algunos analistas junguianos. A partir de ahí se plantea que el proceso creativo es el que expresa el desarrollo en sí de la persona, un sentido del ser que en términos junguianos se arouse in the viewer, the artist manages to establish communication with his audience.

Keywords: Creativity; unconscious; emotions; art.

entiende como individuación, a través del cual se despliegan potencialidades y se integran oscuridades del inconsciente hasta conseguir crear el sí mismo verdadero de cada quien.

\section{Creatividad y proceso creador}

Haríamos bien en considerar el proceso creador como un ser vivo implantado en el alma del hombre.

$$
\text { C. G. Jung }
$$

La creatividad es uno de los principales "factores instintivos" conceptualizados por Jung (citado en Ostfeld, 2006, p. 2). El proceso creador es entendido como "compulsivo" y mantiene vínculos estrechos con la sexualidad, el impulso de actividad y el instinto reflexivo. Asimismo, Jung (citado en Ostfeld, 2006, p. 2) lo pensaba vinculado específicamente a la actividad artística.

Adicionalmente, este autor consideraba el inconsciente como "una fuente inacabable de creatividad", tal y como lo expresa Alonso (2004, p. 58) al explicar a Jung, como capaz de otorgar a la conciencia una fuerza renovadora. Jung $(2000,1992)$ distinguió dos modalidades en la creación artística, correspondientes a cada uno de los niveles del inconsciente, esto es, el primero y más superficial, llamado personal, y el segundo y más profundo, denominado colectivo. En el primer nivel se produce la modalidad de creación psicológica, la cual emerge de la experiencia vivida por el artista creador, en tanto que en el segundo nivel se desarrolla la modalidad de creación visionaria, así nombrada debido a que el artista no posee ninguna familiaridad con la obra creada. 
A Freud le debemos el aporte de la teoría de la creación a partir del inconsciente personal, la cual desarrolla en su obra Psicoanálisis del Arte (1991). Este nivel del inconsciente se alimenta de deseos reprimidos y fantasías originadas en el plano de la existencia humana y particularmente de la persona, que encuentran una vía de expresión en la obra de arte.

En cambio, el artista involucrado en una creación visionaria se convierte, para Jung (citado en Ostfeld, 2006), en una especie de médium, puesto que obedece a un impulso reconocido como superior a sus propias fuerzas y con un "poder que no puede controlar", el cual lo sumerge en una tensión sin medida, como le permite vivir la plenitud de la felicidad (pp. 4-5). Debido a estos efectos en la persona del artista creador, cargados de energías tan opuestas como poderosas, se puede afirmar que la voz del daimón habla a través del creador (Ostfeld, 2006).

Los griegos denominaron daimón a la "fuerza" que induce a la actuación en los momentos de una indecisión significativa para la persona. Y si bien en la antigüedad el daimón se consideraba un ente vinculante entre dioses y mortales, poseyendo cualidades tanto positivas como negativas o destructoras, en el cristianismo las atribuciones positivas y negativas del daimón se separan, asumiéndose los ángeles como seres de luz, mientras los demonios se vinculan a la oscuridad.

Igualmente, el daimón resulta responsable de instaurar las circunstancias propicias para la expresión del ser "más profundo" (Ulloa-Quevedo, s/f, p. 2). Es decir que el daimón tanto empuja a actuar como prepara el contexto favorable para dicha acción cuando se trata de una manifestación del nivel profundo de la psique.

El daimón griego importantizado por Jung y sus seguidores posibilita comprender la autonomía de la psique. En palabras del autor "tan pronto como se empieza a observar la mente, uno se percata del fenómeno autonómico en el cual se existe como espectador o hasta como víctima..." (Jung, 2012, p. 40). Y el poder del inconsciente sobre el vivir puede ser aceptado, pues, por muy arrebatador que sea, no deja de conducir al acto creativo, incluso hasta a la obra artística: "existe una urgencia tremenda en la mente creativa por lograr que un producto de la fantasía tenga una forma relativamente permanente como para poderlo sostener" (Jung, 2012, p. 13).

Jung (citado en Ostfeld, 2006) defendía la cualidad creativa del inconsciente, la cual, a su vez, vinculaba a la fantasía, entendida esta última como "el lugar maternal creativo del hombre" (p. 7). Es decir, que en sus explicaciones, el autor reconoce que el proceso creador se vincula metafóricamente al de una matriz y, por tanto, posee una cualidad femenina: "el trabajo creativo surge de las profundidades inconscientes - podemos decir con veracidad [que] surge del ámbito de la madre" (Ostfeld, 2006, pp. 7-8).

De hecho, Jung (2012) promueve asir la fantasía de tal modo que sea posible presenciar el despliegue de las imágenes que ella trae consigo e intuir, hasta llegar a comprender, el valor que poseen para la persona: “...la regla en lo que concierne a la fantasía es sostener el cuadro que surge hasta que se agoten todas las posibilidades...entonces el juego de las imágenes puede ser observado...” (pp. 37-38).

Si la fantasía y la inspiración dominan, se trata de la intrusión de la fuerza proveniente del inconsciente colectivo y el proceso creativo se vive como un crecimiento interno. El arquetipo de la Madre se evidencia y la obra de arte se siente surgir como un parto, quedando el ego o yo como un acompañante. En el caso de que la obra de arte se viva como una reafirmación de la psique consciente, se 


\section{Rocío Hernández-Mella, Patricia D’Meza-Pérez, Nicole Ramírez-Jiménez, Jose Morel-Camacho, Laura Peña-Lantigua y Cynthia Olivier-Sterling}

encuentra primando el arquetipo del Padre con el cual se glorifican "los aspectos más elevados del canon cultural" (Mora \& Pinto, 2017, p. 14).

Mora \& Pinto (2017) sostienen que el encuentro de la psique con la energía instintiva y abrasadora en el ámbito del selfo el sí mismo genera una transformación que tanto puede manifestarse en una obra artística como en un brote considerado de locura. Esto último ocurre cuando la expresión se asume como psicosis, en vez de admitir el significado profundo que posee la experiencia para la persona, tal y como lo propone Hillman (citado en Ulloa-Quevedo, s/f), conocedor y seguidor de Jung y para quien en todo momento la vivencia, positiva o negativa, abre una posibilidad para la creación.

Hillman (citado en Ulloa-Quevedo, s/f) enfatiza que la motivación para la realización del sí mismo proviene del daimón interior de cada persona, de ahí que se manifieste tanto en las oportunidades que se presentan en la vida como en las puertas que se cierran, en los aciertos como en los fracasos, en las ilusiones como en las obsesiones, y en los arrojos como en los miedos y fobias. El autor junguiano devuelve al ente daimón las luces y sombras concebidas antes por los griegos. Puede ocurrir, entonces, que la fuerza irruptora lleve a una idea negativa que paralice la acción del individuo, sin embargo, ella será para Hillman un camino creativo (Ulloa-Quevedo, s/f).

Para Jung $(2000,1992)$ existe un ser (con minúscula) y otro Ser (con mayúscula). El ser se despliega a partir de las competencias y habilidades adjunto a los deseos y fantasías de vida, cuando se da la oportunidad al individuo de tener una experiencia transformadora, como la que se obtiene a través del arte, en este caso, de una modalidad de creación psicológica. El Ser, en cambio, con mayúscula, alude a una experiencia de vida plena y desbordada, producida por un estado de arrobamiento al nutrirse de la energía del inconsciente colectivo o profundo.

El inconsciente colectivo se relaciona directamente con el "sustrato filogenético de la raza humana", sostenía Jung (citado en Ostfeld, 2006, p. 6), por lo que es anterior a la capacidad de producir conocimiento racional. Esto apoya la afirmación de que existe una energía creadora que no surge de la vida reprimida del artista. Se trata de la creación visionaria, la cual se encuentra fuera del espacio y del tiempo, y que Jung (citado en Ostfeld, 2006) explica que proviene de la "sabiduría arcaica" de ese nivel más profundo del inconsciente (p. 6).

En el proceso creador, tanto el artista como el púbico sensible identifican en la obra de arte una cualidad seductora. Por lo menos es un criterio distintivo del arte moderno, según lo expresa Jung (2012): "el criterio para que sea arte es que logre atraparte" (p. 57). Y especifica que en este tipo de arte se percibe el predominio del proceso interior que vive el artista, quien sustituye el objeto exterior por un derivado subjetivo: "de manera inevitable este proceso desvía el interés fuera del objeto hacia el sujeto y, en vez del objeto real, es el objeto interior el que se convierte en portador de los valores" (Jung, 2012, p. 59).

Como un modo de ampliar lo dicho, Jung (2012) expresa: "de esta manera, el arte moderno nos conduce lejos de esa amplia disgregación de la libido en el objeto exterior hacia esa fuente creativa en nuestro interior, hacia esos valores internos" (p. 60).

Si se trata de la creación visionaria, está visto que es el Sí mismo o Ser de las profundidades quien emerge a través de la obra artística provista de las fuerzas del inconsciente colectivo; sus símbolos ancestrales o arquetipos así plasmados interpelan emociones, nociones y convicciones con un mensaje necesario para la existencia, que lleva a Jung (2012) a manifestar: "el arte aporta un balance a las 
tendencias públicas generales de una determinada época" (p. 57).

¿Es posible que la creatividad pueda ser considerada un valor en un mundo que promueve comportamientos homogéneos? Apreciar la creación no resulta ser una actitud extendida, menos aún si genera conflicto con el statu quo, debido a la cualidad que posee de responder solamente a la propia fuerza o energía instintiva. Por lo menos es lo que acontece en el acto de creación más genuino y, por lo mismo, ha tendido a ser desvalorizado y rechazado.

Si la fuerza creativa, al igual que toda energía, se desprende de la tensión entre opuestos tales como lo femenino y lo masculino, el agua y el fuego, el amor y el miedo, puede conducir a que las vidas modernas estén muy planificadas y provistas de experiencias esperadas sin dejar espacio para lo "oculto", para mitigar el poder del instinto creador (Martínez-Gallardo, 2018, p. 2), originando así una situación que puede ser de cuidado.

Una vida convencional puede llegar al punto de contribuir al surgimiento de una energía creativa destructiva como compensación, puesto que no existe en la psique humana nada totalmente exento de contradicción. Jung (citado en Wilhelm, 2017), explica que "la conciencia no puede asumir posición alguna que no haga surgir en alguna parte de las esquinas oscuras de la psique una negación o un efecto compensatorio" (p. 6).

La creación no puede alcanzarse con el intelecto, en cambio, sí ocurre cuando la psique se permite la influencia del instinto lúdico que actúa por una necesidad interna (Martínez-Gallardo, 2018).

Con la anterior afirmación se hace evidente la importancia del juego, no solamente en el acto creativo, sino también en el desarrollo pleno del sí mismo.
Asimismo, conviene trabajar con medios artísticos diferentes, de manera que el individuo logre encarnarse, lo que quiere decir comprometerse a entrar en la imagen suscitada y dejarse invadir por el símbolo en todos sus sentidos. Es por igual atreverse a dialogar o entrar en relación con las otras imágenes importantes para la expresión creativa encontrada y la escucha de las emociones implicadas en la situación (Duncan, 2007).

Jugar es un instinto, y desde el momento en que la persona abandona el juego no solo pierde su infancia, sino que se aleja de su propia esencia, además de apartarse de la imaginación y de la fantasía, ambas unidas al juego, explica Martínez-Gallardo (2018).

La disminución de la creatividad trae aparejada la pérdida de la espontaneidad y, por consiguiente, de la individualidad. Para Mora \& Pinto (2017) lo que preserva la espontaneidad y la individualidad es la capacidad de jugar: "la creatividad vincula el juego y la tarea, siempre que en ella exista placer y amor por lo que se hace" (p. 14).

\section{Expresión emocional y arte}

Nadie que obvie el arte podrá adentrarse en los recovecos de la experiencia emocional. Iñaki Beti Sáez

Las emociones son una fuente de energía psíquica y funcionan generando un vínculo entre psique y soma. Para Jung (citado por Joan Chodorow, 2004), los afectos representan un estado del sentir, caracterizado tanto por enervaciones físicas determinadas biológicamente, como por "una alteración particular del proceso de ideación” (p. 46).

Se afirma que las emociones resultan ser una forma primaria de comunicación y son más importantes que las palabras. A través de sonrisas, risas y llanto es como el bebé logra llamar la atención y expresarse; 


\section{Rocío Hernández-Mella, Patricia D’Meza-Pérez, Nicole Ramírez-Jiménez, Jose Morel-Camacho, Laura Peña-Lantigua y Cynthia Olivier-Sterling}

si las palabras no se acompañan de las emociones adecuadas, más adelante en el desarrollo, no serán admitidas ni creídas. Tal y como explica Duncan (2007), "cuando expresamos algo con emoción utilizamos gestos, imágenes, metáforas verbales y tonos de voz para comunicarnos mejor con otras personas" (p. 39). Las emociones logran que las palabras cobren vida.

Los afectos son fundamentales en el desarrollo de la comunicación, existiendo emociones innatas que se modulan y transforman dentro de la experiencia familiar. Para ello, el juego y la imaginación resultan ser esenciales. En este proceso de vida, las emociones se convierten en la fuente de los valores, incluyendo aquellos más elevados.

Siguiendo a Jung, Stewart (citado en Chodorow, 2004) enfatiza la relación de los afectos con otras funciones de la psique tal y como son los arquetipos, pero la contribución que se debe resaltar aquí tiene que ver con la imaginación activa $y$, de manera particular, la creatividad.

Stewart (citado en Chodorow, 2004) propone considerar la creación como equivalente al desarrollo, es decir, que ambos se refieren al mismo proceso. Sus años de trabajo junto a niñas y niños le permitieron reconocer que los infantes atraviesan por fases evolutivas de su creatividad que son capaces de plasmar en dibujos y pinturas, danzas, cantos y juegos de dramatización. Ese proceso revela un patrón de etapas regulares y ordenadas: primero de exploración, seguido de asimilación, que conducen al juego imaginativo y al trabajo creativo, y, por último, un estado "centrante" expresado en forma de "mandala", tanto en una pintura como en juegos y otras acciones de creación artística (p. 71).

A Stewart (citado en Chodorow, 2004) se le hizo evidente que lo que Jung había nombrado como individuación se trataba del mismo despliegue que había observado en sus pequeños, ya que ambos se construían a partir de la imaginación activa. Por individuación se entiende un proceso mediante el cual la persona se permite llevar a la conciencia expresiones de la psique profunda o inconsciente colectivo, procurando integrarlas para lograr convertirse en un ser completo y único.

En definitiva, juego e imaginación están completamente intrincados en la infancia y, además, vinculados a los afectos. Esto hace posible que se desarrolle un sentido del ser o del si mismo, tal y como es explicado por Jung $(2000,1992)$, por medio al juego simbólico. En la adultez ocurre de modo equivalente, solo que en esta oportunidad el medio se denomina imaginación activa o creativa.

El juego simbólico de la infancia permite a las nińas y a los niños recapitular las experiencias de vida cargadas de emoción, en el sentido de que la actuación imaginativa posibilita reinterpretar las situaciones difíciles por las que han pasado. Y como el juego se expresa de forma voluntaria, no importa cuán problemática haya sido la circunstancia atravesada, es siempre divertido (Chodorow, 2004).

Stewart (citado en Chodorow, 2004) aporta la explicación acerca de un nivel inicial de la vida donde se crea una unión entre afecto y sensación, con su correspondiente sentido corporal. Los sentidos, adjunto a los afectos esenciales, se modulan y amplifican entre sí, a tal punto que lleva al autor a significar que en un principio las sensaciones pudieron haber sido las precursoras de los afectos. De este modo, el tacto prefigura a la tristeza, el oído al miedo, la vista a la ira o enojo, el olfato y el gusto predeterminan al rechazo y la vergüenza. Por último, el estupor se preconcibe por el sentido propioceptivo o quinestésico. 
En otro orden, si existe una comunión entre el artista y su público es gracias a las emociones que la obra de arte consigue suscitar. En la adultez del artista creador, se hace posible considerar el arte como un lenguaje plasmado en el objeto artístico, gracias a que crea un vínculo comunicativo. La obra de arte representa el proceso de confección de un objeto material y, según la forma en que este se perciba, logrará expresar y transmitir un mensaje de forma física, aunque de contenido espiritual. Incluso, buena parte del valor que se le concede a un objeto artístico tiene que ver con su capacidad de despertar, evocar o generar emociones. A este fenómeno se le conoce como "el valor expresivo de una obra de arte" (Castro, 2017, p. 2).

Asimismo, una obra de arte expresiva encarna la emoción de la persona que la confeccionó a través de un modo particular, y es esta realización la que interesa al público. Al involucrarse en una experiencia creativa, el individuo transforma un objeto cotidiano o una vivencia o idea en una obra con significado y esto es lo que la constituye en obra de arte (Castro, 2017). Vale decir que la obra de arte primero nace en el interior del artista o lo que es lo mismo, la obra de arte en sí es el proceso interno del artista.

Ahora bien, de lo que se ha explicado se desprende que la creación artística va más allá del ámbito psicológico individual, logrando convertirse en una actividad verdaderamente corporativa. Esto ocurre por dos razones principales, una de ellas refiere el hecho del creador de la obra, es compartir una cultura estética con los demás artistas que han influido en él; en tanto que la otra razón destaca a un público que no ejerce una función meramente receptiva, sino que produce la obra junto al artista, gracias a las emociones compartidas entre ambos. Es propio, entonces, afirmar que la obra de arte pertenece a una comunidad (Castro, 2017).

\section{Inconsciente, emoción y creación artística}

"Los elementos creativos se encuentran fuera del intelecto", sentencia Jung (2012, p. 36), para terminar ubicándolos en el inconsciente. La cualidad creativa del inconsciente está vinculada a la fantasía, explica el autor, abundando que se trata de una característica esencial del símbolo que termina formándose.

El inconsciente colectivo, importantizado por Jung, es portador de una "sabiduría arcaica" (Ostfeld, 2006, p. 6), que nos vincula con todo el género humano, lo vivo y lo creado; es decir, nuestra existencia no se circunscribe a una historia personal o tiempo limitado, sobre todo, cuando a lo largo de la vida nos permitimos Ser, con mayúscula; crear nuestra vida: "en la vida del hombre, su historia familiar por sí sola nunca es la llave que conduce hacia sus logros creativos" (Jung, 2012, p. 3).

El artista involucrado en una creación visionaria da paso a su daimón, el cual lo empuja con fuerza, desde el inconsciente colectivo, hacia la solución creativa del impasse que esté experimentando. El arte comparte con los sueños la fantasía y es ella la que guiará a la persona hacia una salida: "contamos con que la fantasía nos liberará del impasse" (Jung, 2012, p. 11). Y, también, es el daimón quien provee las condiciones propicias para el acto creativo. Es propio manifestar, entonces, que la motivación para la realización como seres humanos o el sí mismo, proviene del daimón interior de cada persona.

En el ámbito del Selfo Sí mismo (con mayúscula) la energía que fluye del inconsciente colectivo a la psique es abrasadora y desborda los límites del individuo. Es una experiencia aterradora, si se quiere, que necesita ser canalizada en cualquier forma de expresión creativa. En el proceso, al reconocer la emoción que embarga a la persona y hallar un sentido propio a su existencia, habrá logrado dar unos 


\section{Rocío Hernández-Mella, Patricia D’Meza-Pérez, Nicole Ramírez-Jiménez, Jose Morel-Camacho, Laura Peña-Lantigua y Cynthia Olivier-Sterling}

pasos más en su desarrollo humano esencial, su individuación, o sea, que habrá vivido con hondura de alma.

Es importante no aceptar imposiciones que limiten la expresión creativa o que la señalen como desviada de los cánones de la normalidad, pues cualquiera que sea la vivencia, aún se reconozca como negativa, ella abre oportunidades para la creación: "la vida a menudo demanda la ejecución de nuevas formas que resultan enteramente inaceptables para la época en que vivimos, pero no podemos permitir encogernos en cuanto a tomar esas nuevas vías por tal razón" (Jung, 2012, p. 11).

Lo mismo que el inconsciente, las emociones proporcionan energía a la psique y resultan ser un vínculo entre ella y el propio cuerpo. Más importantes que las palabras, las emociones son nuestra primera forma de comunicación entre el bebé y su madre, y las que otorgan el sentido a las frases dichas, más allá de su significado convencional (de diccionario), puesto que se comparte un mismo campo de energía emocional, en una familia, en el aula de clases o en un grupo de danza.

Si bien existen emociones innatas, estas van transformándose en la experiencia de vivir y en ese desarrollo resaltan el juego y la imaginación como procesos insoslayables. El juego se destaca porque desde el nacimiento y en la infancia el bebé, la niña o el niño no establece una diferencia entre una acción puramente lúdica o una acción con intención de aprender, mientras que tanto la imaginación como la fantasía sobresalen cuando se trata de un accionar creativo o transformador, animado por el inconsciente.

Es así como juego e imaginación son piezas clave del despliegue del ser o del sí mismo y del Selfy ambos procesos definen la acción creativa del ser humano. Entonces, el desarrollo humano pasa a definirse por el progreso o perfeccionamiento de la creatividad, la creación artística, imbricada en la emoción y alimentada por la fuerza del inconsciente.

Se puede observar en niñas y niños involucrados en un juego simbólico cómo este les posibilita reconvertir las experiencias vividas como negativas y cargadas de emociones fuertes, ya que la actuación imaginativa permite reinterpretar las situaciones pasadas. Igualmente, en la adultez las emociones continúan tendiendo puentes, esta vez entre la obra artística y un público que sea sensible a ella. Artista y público quedan comunicados y, a la vez, transformados por la emoción envuelta en la obra creada. El símbolo originado en la creación artística, por las fuerzas del inconsciente, sobre todo del estrato profundo o colectivo del artista, interpela la interioridad de ese público, tocando sus fibras emocionales.

\section{Conclusión}

En este trabajo se ha destacado la creación como fuerza transformadora que consigue promover el despliegue del self. En ese sentido, el proceso creador no solo es una forma de conocimiento como lo es la ciencia, sino que también constituye un medio de comunicación a través del cual el ser humano puede expresarse. De igual forma, mediante la creación artística y las representaciones de la realidad física y humana, la persona pone de manifiesto vertientes del psiquismo propio como son los afectos, las emociones y los sentimientos, tanto para sí misma como para otros.

Las emociones básicas son: el miedo, la rabia, la alegría, el amor y la tristeza, así como los sentimientos, aún aquellos que puedan incomodar a la persona, son relevantes en su proceso de desarrollo. Todas las expresiones afectivas son necesarias, a través de las cuales se ejerce el ser personal; los afectos, las emociones y los sentimientos inciden en las capacidades cognoscitivas, en la salud física y en el rendimiento profesional. 
De lo expresado se desprende la necesidad de contar con un recurso que promueva el equilibrio emocional. Para Duncan (2007) esto se logra con las artes y, por lo tanto, expresa que "el uso de las artes será de interés en el trabajo terapéutico tanto para encontrar lo que ocurre a nivel inconsciente, como para crear la posibilidad de mejora" (p. 44). Esto es, que el arte promueve el bienestar. Los diferentes lenguajes artísticos y sus manifestaciones poseen el poder de animar a la persona que entra en contacto con ellos a sentir de forma vívida y atreverse a explorar dentro de sí cada vez más profundamente, a ir liberando tensiones emocionales y a recrearse como ser completo.

Ahora bien, es cierto que a través del objeto de arte el ser humano complace sus necesidades estéticas de conocimiento, pone de manifiesto su manera de pensar, su subjetividad, y su forma de percibir la realidad. Pero también ocurre que ese objeto creado proporciona en el individuo la oportunidad de lograr un lazo afectivo entre su personalidad, la estructura cultural de la época y el medio social en el cual se desenvuelve, y que de alguna forma lo condiciona; por medio de la creación artística hasta lo puede llegar a modificar (Ros, 2005). Si se quiere alcanzar el bienestar y la felicidad, hace falta convocar el arte como parte de la vida.

\section{Referencias}

Alonso, J. C. (2004). La psicología analítica de Jung y sus aportes a la psicoterapia. Universitas Psicológica. 3(1), 55-70

Castro, S. (2017). Una aproximación al complejo emotivo del arte. Aisthesis. 62(4), 67-83

Chodorow, J. (2004). Dance Therapy \& Depth Psychology. The moving imagination. New York, Estados Unidos: Brunner-Routledge.

Duncan, N. (2007). Trabajar con las Emociones en Arteterapia. Arteterapia. Papeles De Arteterapia Y Educación Artística Para La Inclusión Social, 2, 39-49
Freud, S. (1991). Psicoanálisis del arte. Madrid, Espańa: Alianza Editorial.

Jung, C. (1992). Formaciones de lo Inconsciente. Barcelona, España: Paidós. Psicología Profunda.

Jung, C. (2000). Lo Inconsciente. Buenos Aires, Argentina: Editorial Losada, S. A.

Jung, C. (2012). Introduction to junguian psychology. Inglaterra: Princeton University Press.

Martínez-Gallardo, A. (2018). "¿Qué detona la creatividad: el juego, la fantasía, el erotismo? La Psicología Profunda lo explica”, [en línea]. Pijamasurf. Recuperado de:https://pijamasurf. com/2018/04/que_detona_la_creatividad_el_ juego_la_fantasia_el_erotismo_la_psicologia_ profunda_lo_explical

Mora, C. \& Pinto, C. (2017). Creatividad y Locura: esa delgada línea, [en línea]. ADEPAC. Recuperado de: http://www.adepac.org/inicio/ creatividad-y-locura-esa-delgada-linea-carolina-mora-y-carmen-pinto/

Ostfeld, T. (2006). Creación "psicológica” y "visionaria” arquetípica. Una perspectiva desde la Psicología Analítica junguiana, [en línea]. Recreart. Recuperado de: http://www.iacat.com/ Revista/recrearte06.htm

Ros, N. (2005). El lenguaje Artístico, la educación y la creación. Buenos Aires, Argentina: Universidad Nacional Centro de la Provincia de Buenos Aires.

Ulloa-Quevedo, D. (s/f). "El 'daimón' o impulso creativo, un concepto de Carl Jung", [en línea] Psicología y Mente. Recuperado de: https://psicologiaymente.net/psicologia/daimon-impulso-creativo-carl-jung

Wilhelm, D. (2017). Vivenciando los mundos internos: la imaginación activa y su relación con el proceso de individuación y el desarrollo de la personalidad, [en líneas]. Centro Jung de Buenos Aires. Recuperado de: http:// www.centrojung.com.ar/imaginacion_activa_ individuacion_desarrollo_de_la_personalidad.htm 


\section{Datos de diliacion}

El artículo es resultado de un grupo de estudiantes egresados de la carrera de Psicología del INTEC junto a la profesora:

Rocío Hernández Mella. Profesora-investigadora del Área de Ciencias Sociales y Humanidades del Instituto Tecnológico de Santo Domingo (INTEC). Doctora en Psicología Social; maestría en Planificación y Administración de la Educación; especialización en Psicología Educativa y licenciatura en Psicología. Consultora en Psicología y Educación para OEI-República Dominicana y el MINERD; coordinadora Educativa del Centro Jung Santo Domingo y vicepresidenta de la Fundación Tonucci: Educando para la Diversidad. 